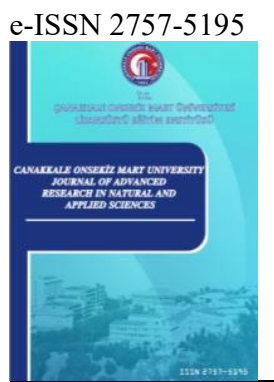

Çanakkale Onsekiz Mart University

Journal of Advanced Research in Natural and Applied Sciences

Open Access

\title{
Mısırda Toplam Fenolik ve Antosiyanin İçeriğinin Belirlenmesi için Geliştirilmiş NIRS (Yakın Kızıl Ötesi Spektroskopisi) Kalibrasyon Modelleri Üzerine Kemometrik Yöntemlerin Etkisi
}

\author{
Mehmet Şerment ${ }^{1}$, Fatih Kahriman ${ }^{2}$ \\ ${ }^{1}$ Tarla Bitkileri Anabilim Dalı, Lisansüstü Eğitim Enstitüsü, Çanakkale Onsekiz Mart Üniversitesi, Çanakkale, Türkiye \\ ${ }^{2}$ Tarla Bitkileri Bölümü, Ziraat Fakültesi, Çanakkale Onsekiz Mart Üniversitesi, Çanakkale, Türkiye
}

$\begin{array}{lr}\text { Makale Tarihçesi } \\ \text { Gönderim: } & 20.02 .2021 \\ \text { Kabul: } & 03.06 .2021 \\ \text { Yayım: } & 20.09 .2021 \\ \text { Araştırma } & \text { Makalesi }\end{array}$

Araştırma Makalesi

\begin{abstract}
Öz -Bu çalışmada öğütülmüș mısır örneklerinde toplam antosiyanin ve fenolik içeriklerinin yakın kızıl ötesi (NIR) spektroskopisi ile tespitine yönelik geliştirilmiş kalibrasyon modellerinde, spektral ön işlem ve dalga boyu seçim yöntemlerinin tahmin başarısına etkisi araştırılmıştır. Araştırma materyali olarak 200 farklı mısır örneği kullanılmıştır. Çalışmada ön işlem olarak; birinci türev (FD), ikinci türev (SD), standart normal değişim (SNV) ve bu yöntemlerin birlikte kullanıldığı 2 farklı kombinasyon karşılaştırılmıştır. Spektral veriler 2 farklı dalga boyu seçim yöntemi (VIP ve SR) ile ayrı ayrı işleme alınmıştır. Ön işlem ve dalga boyu seçim yöntemlerinin uygulanmasından sonra hedef değișkenlerin tahmini için iki farklı model olușturma tekniğinden (PLS ve SVMR) faydalanılmıștır. Böylelikle, çalışmada toplam fenolik ve toplam antosiyanin içeriği için 36'ar model kıyaslanmıştır. Oluşturulan modeller dış doğrulama işlemine tabi tutularak model güvenilirlikleri test edilmiştir. Çalışma sonucunda mısır tanesinde antosiyanin ve fenolik bileşen içeriğinin tespitinde kullanılan kemometrik yöntemin, model başarısını arttırdığ görülmüştür. Çalışmada karşılaştırılan modellerden antosiyanin içeriği için FD-SNV-SR kombinasyonu ile oluşturulan modelin $\left(\mathrm{RMSE}_{\mathrm{Cal}}=0.02, \mathrm{R}_{\mathrm{Cal}}^{2}=0.96, \mathrm{RPD}_{\mathrm{Cal}}=5.36, \mathrm{RMSE}_{\mathrm{Val}}=0.03, \mathrm{R}_{\mathrm{Va}}^{2}=0.90, \mathrm{RPD}_{\mathrm{Val}}=3.14\right)$ tahmin başarısı yüksek bulunmuştur. Fenolik bileşen içeriği için ise PLS modelleme tekniği daha başarılı $\left(\operatorname{RMSE}_{\text {Cal }}=0.06\right.$, $\mathrm{R}^{2} \mathrm{Cal}=0.66, \mathrm{RPD}_{\mathrm{Cal}}=1.71, \mathrm{RMSE}_{\mathrm{Val}}=0.07, \mathrm{R}_{\mathrm{Val}}^{2}=0.46, \mathrm{RPD}_{\mathrm{Val}}=1.38$ ) bulunmuştur. Sonuç olarak, uygulanan kemometrik yöntemlerin NIR ile sekonder bileşen tespitine katkı sunduğu belirlenmiştir.
\end{abstract}

\section{The Effect of Chemometric Methods on NIRS (Near Infrared Reflectance Spectroscopy) Calibration Models for Determination of Total Phenolic and Anthocyanin Contents in Maize}

\begin{abstract}
Article History
Received: $\quad 20.02 .2021$

Accepted: $\quad 03.06 .2021$

Published: $\quad 20.09 .2021$
\end{abstract}

Research Article

\begin{abstract}
In this study, the effect of spectral pretreatment and wavelength selection method combinations for determination of total anthocyanin and phenolic contents by near infrared (NIR) spectroscopy on prediction success was investigated. Two hundred maize samples were used as experimental material. As a pre-treatment in the study; First derivative (FD), second derivative (SD), standard normal variate (SNV) were compared with 2 different combinations using these methods together. Spectral data were processed separately with the combination of 2 different wavelength selection methods (VIP and SR). After applying pretreatment and wavelength selection methods, two different model generation techniques (PLS and SVMR) were used to estimate the target variables. Thus, 36 different models each were compared for total anthocyanin and phenolic contents in the study. The model reliability was tested by subjecting the created models to external validation. Results showed that the chemometric method used to determine the anthocyanin and phenolic component content in corn grain increased the model success. Estimation of the model $\left(\mathrm{RMSE}_{\mathrm{Cal}}=0.02, \mathrm{R}_{\mathrm{Cal}}^{2}=0.96, \mathrm{RPD}_{\mathrm{Cal}}=5.36, \mathrm{RMSE}_{\mathrm{Val}}=0.03, \mathrm{R}^{2} \mathrm{Val}=0.90, \mathrm{RPD}_{\mathrm{Val}}=3.14\right)$ for anthocyanin content its success was found to be high. For the phenolic content, PLS modeling technique was found to be more successful $\left(\mathrm{RMSE}_{\text {Cal }}=0.06, \mathrm{R}_{\text {Cal }}^{2}=0.66, \mathrm{RPD}_{\mathrm{Cal}}=1.71, \mathrm{RMSEVal}=0.07, \mathrm{R}_{\text {Val }}^{2}=0.46, \mathrm{RPD}_{\text {Val }}=1.38\right)$. As a result, it has been determined that chemometric method applications contribute to secondary component detection with NIR.
\end{abstract}

Keywords - Regression, seconder metabolites, wavelength selection, Zea mays

1 (D) mehmet_serment@hotmail.com

2 (1) fkahriman@hotmail.com

*Corresponding Author 


\section{Giriş}

Sekonder metabolitler diğer bitki türlerinde olduğu gibi misırda da ürün kalitesini etkileyen önemli bileşenlerdir. Bu bileşenler içerisinde antioksidan etkiye sahip olan fenolik bileşikler ve antosiyaninler hem beslenme hem de sağlık açısından önemlidir. Flavonolid bileşiklerinin en önemli grubunu oluşturan antosiyaninler mısır tanesine renk vermektedir. Renkli mısır genotipleri ise çok uzun yıllardan beridir tatlandırıcı ve renklendirici olarak yetiştirilmekte ve tüketilmektedir (Jing vd., 2005). Fenolik bileşikler ise biyokimyasal olaylarda oksidatif etkileri azaltan ve bitkinin hayatsal faaliyetlerinde rolleri olan biyokimyasallardır. Yulaf, buğday ve prinç ile kıyaslandığında en yüksek antioksidan etki ve fenolik bileşen içeriği mısırdadır (Adom ve Liu, 2002). Mısırın beslenmedeki payı dikkate alındığında bu bileşenlerin artırılması arzu edilmektedir. Bu amaçla son yıllarda antioksidan kapasitesi yüksek mısır genotiplerinin geliştirilmesi için önemli bir çaba harcanmaktadır (Ji vd., 2010). Bu yönde yapılan araştırmalarda ise kullanılan örneklerde antosiyanin ve fenolik bileşenlerin analiz edilmesine ihtiyaç duyulmaktadır.

Antosiyanin analizlerinde genel olarak özütleme işleminin ardından farklı ölçüm cihazları ve yöntemleri kullanılmaktadır. Bu yöntemlerin başında yüksek basınçlı sıvı kromotografisi, ince tabaka kâğıt kromotografisi ve son yıllarda güncel hale gelen nükleer manyetik rezonans spektroskopisi gelmektedir (Keleş, 2015). Fenolik bileşenler de antosiyaninlere benzer şekilde özütleme sonrasında kromotografik ya da UV-görünür spektroskopik yöntemler kullanılarak analiz edilebilmektedir. Ancak bu analiz yöntemleri uzun zaman harcanan, yüksek emek ve iş gücü gerektiren, kimyasal sarfının yüksek işlemlere ihtiyaç duymaktadır. Bu nedenle antosiyanin ve fenolik bileşenlerin kısa sürede ve kimyasal harcanmayan çevreci analiz yöntemlerinin geliştirilmesi gerekmektedir. Bu konuda yakın kızıl ötesi spektroskopisi (NIR) önemli alternatiflerden birisidir. Zira NIR spektroskopisi tahıl ürünlerinde farklı biyokimysal bileşenlerin tespitinde başarılı sonuçlar vermiştir. Bu kapsamda mısır ununda farklı biyokimyasal bileșenlerin tespiti (Baye vd., 2006; Egesel ve Kahrıman, 2012; Egesel vd., 2016; Kahrıman vd., 2019; Kahrıman vd., 2020) için NIR spektroskopisinin kullanıldığı çeşitli araştırmalar yürütülmüştür. Bu çalışmaların yanı sıra mısırda antosiyanin içeriğinin belirlenmesi amaciyla tahmin modellerinin geliştirilmesini konu edinen örnek çalışmalar yapılmıştır (Mangalvedhe vd., 2015). Ayrıca geliştirilen NIR kalibrasyon modellerinin farklı mısır genotipleri karakterize etmek amacıyla bazı araştırmalar yapılmıştır (Redaelli vd., 2016). Özellikle mısır tanesinde diğer biyokimyasal bileşenler üzerine çok sayıda araştırma yürütülmüş olmasına karşın, toplam fenolik ve antosiyanin içerinin NIR ile tespitini konu edinen sınırlı sayıda araştırmaya rastlanmıştır (Mangalvedhe vd., 2015; Meng vd., 2015; Redaelli vd., 2016). $\mathrm{Bu}$ araştırmaların büyük kısmı modelleme tekniği olarak klasik yaklaşımların kullanılmış olduğu araştırmalardır. Bunların yanı sıra antosiyanin ve fenolik içeriğinin tespitini konu edinen mevcut araştırmalarda kemometrik yöntemlerin çeşitliliğinin ve model başarısına etkisini kapsamlı olarak ele alınmamıștır.

Kemometrik uygulamalar, spektral verilerdeki düzensizliklerin giderilmesi, hedef değişkenle ilişkili dalga boylarının seçilmesi, seçilen dalga boyuna sahip tahmin modellerinin geliştirilmesi ve doğrulanması gibi üç temel adımı içermektedir (Kahrıman ve Egesel, 2018). Spektral verideki istenmeyen değişimlerin ortadan kaldırılması için uygulanan birinci adımda kullanılan tekniklerden bazıları, birinci türev (FD), ikinci türev (SD), Çoklu Saçılma Düzeltmesi (MSC), Standart Normal Değişim (SNV) ve farklı değişken seçim yöntemleri gibi çeşitli geleneksel yöntemlerdir (Yi vd., 2016). FD ve SD gibi türev alma işlemleri üst üste binen spektral piklerin düzeltilmesi ile sinyal düzeltmesi sağlayan yöntemlerdir (Agelet ve Hurgburg Jr., 2010). MSC ve SNV ise reflektans ölçümlerinde ışık saçılmından kaynaklı bozulmaları gidermek amacıyla yaygın olarak kullanılan yöntemlerdir (Agelet ve Hurgburg Jr., 2010). Kemometrik uygulamalar içerisinde değişken seçimi amaciyla yaygın olarak kullanılan yöntemler ise; Ardışık Projeksiyonlar Algoritması (SPA), Rekabetçi Uyarlanabilir Yeniden Ağırlıklandırılmış Örnekleme (CARS), Rassal Orman (RF), Değişken Önemlilik Projeksiyonları (VIP), Seçicilik Oranı (SR) yöntemleridir (Lao vd., 2020). Bunlar, spektral veride yer alan değişkenlerin 
kalibrasyona konu olan değişkenlerle ilgili olanları veya ilişkisiz olanları belirlemeye imkân vermektedir. Değişken seçim yöntemlerinin kullanılması spektral veride hedef değişken ile en fazla ilişkili olan dalga boylarının modelde kullanılmasına ve daha doğru tahmin sonuçları alınmasına imkân vermektedir. Klasik yöntemler olan kabul edilen modelleme tekniklerinin başlıcaları ise Çoklu Doğrusal Regresyon (MLR) Temel Bileşen Regresyonu (PCR) ve Kısmi En Küçük Kareler Regresyonu (PLSR) yöntemleridir ancak bu yöntemler 1şık ile madde arasında doğrusal olmayan ilişkileri yeterince açıklayamamaktadır (Pasquini, 2003). Klasik yöntemlere alternatif olarak geliştirilen ve doğrusal olmayan modelleme teknikleri ise daha çok makine öğrenmesine dayalı yaklaşımlara dayanmaktadır ve ön öğrenmeli ya da ön öğrenmesiz olarak sınıflandırılır. Öğrenme tabanlı olmayan modeller, spektral verilerin genel yapısını anlamak için kullanılırken, öğrenme bazlı modeller önceden bilinen veri yapılarına dayanmaktadır (Yi vd., 2016). Bu yöntemler içerisinde Yapay Sinir Ağları (ANN), Destek Vektör Makineleri (DVM) gibi yöntemler sepktral model geliştirme amacıyla yaygın kullanılan tekniklerdendir (Agelet ve Hurgburg Jr., 2010). Spektral model geliştirme adımlarında kemometrik yöntemlerin çeşitli kombinasyonlarının kullanımı, tarımsal ürünlerde biyokimyasal bileşenlerin analizinde NIR cihazlarından yararlanma imkânını artırmaktadır. Bu nedenle NIR tahmin modellerinde hedef değişkene göre uygun kemometrik uygulamaların belirlenmesi önem arz etmektedir.

Bilimsel literatürdeki çalışmalar dikkate alındığında, antosiyanin ve fenolik bileşenler gibi sekonder metabolitlerin NIR ile tespitinde kemometrik yöntemlerin etkisinin yeteri düzeyde araştırılmadığı görülmüştür. Ülkemiz kaynaklı literatürde ise NIR ile toplam antosiyanin ve fenolik içeriğinin belirlenmesini konu edinen herhangi bir çalışmaya ulaşılamamıştır. Bu araştırma öğütülmüş mısırlarda antosiyanin ve fenolik bileşenlerin NIR ile tespitinde farklı ön işlem (Ön işlemsiz, FD, SD, SNV, FD+SNV, SD+SNV), dalga boyu seçim yöntemleri (Tüm spektrum, VIP ve SR) ve modelleme tekniklerinin (PLS ve SVM) etkisini ortaya koymak amaciyla yürütülmüştür. Ayrıca bu çalışmada hedef değişkenler ile spektral veri toplanan bölgedeki dalga boylarının ilişkisi de incelenmiştir.

\section{Materyal ve Yöntem}

\subsection{Materyal}

Çalışmada toplam 200 farklı dane mısır örneği kullanılmıştır. Bu örneklerin tamamı Çanakkale Onsekiz Mart Üniversitesi, Ziraat Fakültesi Tarla Bitkileri Bölümü’nde 2019 yılında yürütülen mısır 1slah çalışmalarından elde edilmiştir. Kullanılan örnekler tane rengi bakımından farklı özelliklere (beyaz, sarı, turuncu, mor) sahip genotiplere ait olsa da büyük kısmı mısırda yaygın görülen tane rengi özelliklerini taşımaktadır. Mısır örnekleri, analize kadar laboratuvarda $+4{ }^{\circ} \mathrm{C}^{\prime}$ de muhafaza edilmiştir. Analiz edilecek örnekler laboratuvar değirmeninde 0.5 mm'lik elekle ögütülmüştür.

\section{2. Ölçümlenen Özellikler}

Toplam Antosiyanin İçeriği (mg/kg): Örneklerin antosiyanin içerikleri Abdel-Aal ve Hucl (1999) tarafindan önerilen yönteme göre tespit edilmiştir. Bu amaçla $500 \mathrm{mg}$ ögütülmüş numune $10 \mathrm{ml} 1 \mathrm{~N}$ metanolik HCI (\%85:15) içerisinde $30 \mathrm{dk}$ oda sıcaklığında çalkalanmıştır. Daha sonra örnekler 8000 g'de $20 \mathrm{dk}$ santrifüj edilmiştir. Her bir örneğin üst fazından 200 mikrolitre alınarak 96 kuyucuklu mikroplaya konulmuş ve $535 \mathrm{~nm}$ ve $700 \mathrm{~nm}$ absorbans değerleri alınarak cyanidin 3-glucoside eşdeğeri cinsinden (mg/kg CGE) antosiyanin içerikleri belirlenmiş̧ir.

Toplam Fenolik Bileşen İçeriği (\%): Toplam fenolik bileşen analizlerinde Uluslararası Buğday ve Mısır Araştırmalar Merkezi (CIMMYT) tarafından geliştirilen metot kullanılmıştır (Galicia vd., 2009). Bu amaçla $20 \mathrm{mg}$ öğütülmüş örnek üzerine $1.3 \mathrm{ml} 1.2 \mathrm{M} \mathrm{HCI}$-Metanol çözeltisi eklenerek $42^{\circ} \mathrm{C}^{\prime}$ de $1100 \mathrm{rmp}$ 'de $30 \mathrm{dk}$ çalkalanmıştır. Örnekler oda sıcaklığına geldikten sonra 14000 rpm'de 5 dakika santrifüj edilmiştir. 500 mikrolitre üst faz alınarak yeni bir ependorf tüpüne konulmuş ve evaporatörde kurutulmuştur. Kurutulan örnek 
$1.3 \mathrm{~m}$ metanol içerisinde çözülerek kolorimetrik reaksiyona tabi tutulmuştur. Bu amaçla, her bir örnekten 50 mikrolitre alınarak 96 gözenekli mikroplakaya konulmuştur. Örneklerin üzerine 40 mikrolitre \%25'lik FolinCiolalteu solüsyonu eklenmiş, ardından 110 mikrolitre $400 \mathrm{mM} \mathrm{Na} \mathrm{CO}_{3}$ ilave edilmiştir. Mikroplaka 800 rmp'de 10 saniye çalkalandıktan sonra örnekler $42{ }^{\circ} \mathrm{C}$ 'de 9 dakika inkübasyona tabi tutulmuştur. Ardından örneklerin $765 \mathrm{~nm}$ 'de absorbans değerleri alınarak gallik asit ile oluşturulan standart kürve yardımıyla örneklerin fenolik bileşen içerikleri gallik asit eşdeğeri (\%GAE) tespit edilmiştir.

\subsection{Spektral Modellerin Geliştirilmesi ve Doğrulanması}

Öğütülmüş örnekler masaüstü NIRS cihazının (Spectrastar 2400D, Unity Scientific, ABD) döner kap modu kullanılarak, 1200-2400 nm arasında her bir dalga boyuna ait spektral veri alınmıştır. Örneklerden spektral veri toplanırken toplam 48 farklı noktadan ölçüm yapılmış ve bu ölçümlerin ortalaması örnek spektrumu olarak kaydedilmiştir. Örnek spektrumları jdx formatında birleştirilerek kalibrasyon oluşturma çalışmalarında kullanılmak üzere metin (.txt) dosyalarına dönüştürülmüştür. Tahmin modelleri oluşturulmadan önce tüm veri seti kullanarak tip dışı örnekler uzaklaştırılmış ve kalan 200 adet örnek kalibrasyon $(n=150)$ ve diş doğrulama seti $(\mathrm{n}=50)$ olmak üzere iki alt gruba ayrılmıştır. Bu ayrım işleminde Kennard-Stone algoritmasından yararlanılmıştır. Çalışmada 6 farklı ön işlem, 3 farklı seçim yöntemi ve 2 farklı modelleme tekniği kullanılmıştır (Tablo 1). Her önişleme ait spektral veri her bir dalga boyu seçim yöntemi ile muamele edildikten sonra, her bir modelleme yöntemi ile ayrı ayrı analiz edilmiştir. Böylelikle incelenen her bir özellik için toplam 36 farklı model oluşturulmuş ve değerlendirmeye alınmıştır. Çalışmada kullanılan önişlemler spektral modelleme çalışmalarında yaygın kullanılan yöntemlerden seçilmiş olup, bu yöntemlerle ilgili bilgiler giriş bölümünde sunulmuştur.

Tablo 1

Çalışmada kullanılan kemometrik teknikler ve modelleme yöntemleri

\begin{tabular}{lll}
\hline Ön İşlem & Dalga Boyu Seçim Yöntemi & Modelleme Tekniği \\
\hline 1) Ön İşlemsiz & 1) Tüm Spektral Veri & $\begin{array}{l}\text { 1) Kismi En Küçük Kareler Reg. } \\
\text { (PLS) }\end{array}$ \\
2) Birinci Türev (FD) & 2) Değişken Önemlilik Projeksiyon. & 2) Destek Vektör Makin. (SVM) \\
3) İkinci Türev (SD) & 3) Seçicilik Oranı (SR) \\
4) Standart Normal Değişim (SNV) & & \\
5) FD+SNV & & \\
6) SD+SNV & \\
\hline
\end{tabular}

Önişlemler ve modelleme çalışmalarında R programında (R Core Team, 2019) geliştirilen SelectWave web uygulaması (Kahrıman ve Liland, 2021) kullanılmıştır. SelectWave uygulaması ( https://bafr.shinyapps.io/SelectWave/2 internet üzerinden farklı kemometrik uygulamalar ile tahmin modeli geliştirmeye imkân veren bir uygulamadır. Bu uygulamaya yüklenen spektral veri ve referans analiz sonuçlarından elde edilen modeller için kalibrasyon setine $(n=150)$ ait $\mathrm{RMSE}_{\mathrm{Cal}}, \mathrm{R}^{2}$ Cal ve $\mathrm{RPD}_{\mathrm{Cal}}$ değerleri ile kalibrasyon seti dışında ( $\mathrm{n}=50$ ) örneklerle yapılan dış doğrulama setinde $\mathrm{RMSE}_{\text {Val }}, \mathrm{R}^{2}{ }_{\text {val }}$ ve $\mathrm{RPD}_{\text {Val }}$ istatistikleri hesaplanmıştır. Oluşturulan modeller bu istatistiklere göre değerlendirilmiş olup, RMSE değeri düşük, $\mathrm{R}^{2}$ ve RPD değerleri yüksek modeller başarılı tahmin veren modeller olarak kabul edilmiştir. RPD değerleri Sans vd. (2020) tarafından önerilen skalaya göre yapılmıştır. Bu skalada modeller iyi (RPD $>2)$, orta $(1.4<\mathrm{RPD}<2)$, zayıf (RPD < 1.4) olmak üzere üç sınıfa ayrılmıştır. Değerlendirme yapılırken önce kalibrasyon setine ve dış doğrulama setine ait istatistiklerin her ikisi için de yukarıdaki şartı sağlayan modeller başarılı kabul edilmiştir. 


\section{Bulgular ve Tartışma}

\subsection{Antosiyanin ve Fenolik İçeriği Bakımından Örnek Setindeki Değiş̧im}

$\mathrm{Bu}$ çalışmada kalibrasyon ve diş doğrulama setinde bulunan istatistikler Tablo 2ª de gösterilmiştir. Antosiyanin içeriği bakımından kalibrasyon setinde bulunan aralık (\%0.02 CGE ve \%0.47 CGE) değerlerine göre dış doğrulama setindeki örneklerin antosiyanin içeriği setine ait sınırlar içerisindedir. Antosiyaninler mısır tanesinde renk oluşumuna neden olan bileşenlerdir ve genellikle mor-kırmızı renk oluştururlar (Lago vd., 2014). Çalışmamızda kullanılan öğütülmüş mısır örneklerinin beyaz, sarı, turuncu, mor ve kırmızı tane renkli mısırlar bulunmaktadır. Bu durum antosiyanin içeriğine yönelik analiz sonuçlarını ve tanımlayıcı istatistikleri doğrudan etkilemiştir.

Fenolik bileşenler mısır ununda antioksidan etkiye sahip olan biyokimyasallardır. Kalibrasyon seti ve dış doğrulama setinde fenolik asit içeriğinin çok yakın ortalama sahip olduğu buna karşın diş doğrulama setindeki değişimin kalibrasyon setinden daha yüksek olduğu görülmektedir (Tablo 2). Lopez-Martinez vd. (2009) mısır ununda ortalama fenolik asit içeriğini $343 \mathrm{mg} \mathrm{GAE} / 100 \mathrm{~g}$ (\%0.343) olarak rapor etmiştir. Çalışmamızda elde edilen ortalamanın bu değerin üzerinde olduğu tespit edilmiştir. Bu durum çalışmamızda kullanılan genotip sayısının fazla olmasına ve kullanılan materyalde genetik çeşitlilik bakımından yüksek bir varyasyon bulundurmasına bağlanabilir. Nitekim az sayıda ve genetik çeşitlilik bakımından sınırlı değişim gösteren materyallerle yürütülen bir çalışmada toplam fenol içeriği 112.05- $244.90 \mu \mathrm{g}$ GAE/g (\%0.11-\%0.25 GAE) arasında bulunmuştur (Sabanc1, 2016).

Tablo 2

Antosiyanin ve fenolik bileşenler için örnek setlerinde tanımlayıcı istatistikler.

\begin{tabular}{lllll}
\hline & \multicolumn{1}{l}{ Antosiyanin (mg CGE/kg) } & \multicolumn{2}{l}{ Fenolik Bileşen (\% GAE) } \\
\hline Örnek Seti & Kalibrasyon & Dış Doğrulama & Kalibrasyon & D1ş Doğrulama \\
\hline $\mathrm{N}$ & 150 & 50 & 150 & 50 \\
Ortalama & 0.14 & 0.12 & 0.67 & 0.67 \\
S. Sapma & 0.09 & 0.08 & 0.09 & 0.09 \\
Minimum & 0.02 & 0.01 & 0.41 & 0.52 \\
Maksimum & 0.47 & 0.37 & 0.96 & 0.91 \\
\hline
\end{tabular}

\subsection{Kalibrasyon Modellerinin Değerlendirilmesi}

Antosiyanin içeriğine yönelik oluşturulan PLS tahmin modelleri için bulunan değerler Tablo $\underline{3}$ 'de, SVM model değerlendirme sonuçları ise Tablo 4'de gösterilmiştir. PLS yönteminde, FD+SNV önişlemi ve VIP dalga boyu kombinasyonundan $\left(\mathrm{RMSE}_{\mathrm{Cal}}=0.03, \mathrm{R}_{\mathrm{Cal}}^{2}=0.87, \mathrm{RPD}_{\mathrm{Cal}}=2.88, \mathrm{RMSE}_{\mathrm{Val}}=0.05, \mathrm{R}_{\mathrm{Val}}^{2}=0.74\right.$, $\left.R_{P D} D_{V a l}=1.97\right)$ diğer veri seti kombinasyonlarından daha başarılı sonuçlar elde edilmiştir. SVM modelleri içinde $\mathrm{FD}+\mathrm{SNV}+\mathrm{SR}$ kombinasyonu ile oluşturulan modelin diğer modellerden daha iyi sonuç verdiği görülmüştür. Düşük hata ve yüksek $\mathrm{R}^{2}$ ve $\mathrm{RPD}$ değeri veren bu modelin $\left(\mathrm{RMSE}_{\mathrm{Cal}}=0.02, \mathrm{R}_{\mathrm{Cal}}{ }=0.96\right.$, $\left.\mathrm{RPD}_{\mathrm{Cal}}=5.36, \quad \mathrm{RMSE}_{\mathrm{Val}}=0.03, \quad \mathrm{R}^{2} \mathrm{Val}=0.90, \quad \mathrm{RPD}_{\mathrm{Val}}=3.14\right)$ antosiyanin içeriğinin belirlenmesinde kullanılabileceği saptanmıştır (Tablo 3, Şekil 1). Tüm spektral verinin herhangi bir ön işlem uygulanmadan kullanıldığı PLS modeli $\left(\mathrm{R}^{2}\right.$ Cal $\left.=0.15, \mathrm{R}^{2}{ }_{\mathrm{Val}}=0.10\right)$ ile bu modelin $\mathrm{R}^{2}$ değerleri kıyaslandığında $\left(\mathrm{R}^{2}{ }_{\mathrm{Cal}}=0.96\right.$, $\mathrm{R}^{2}{ }_{\mathrm{Val}}=0.90$ ), spektral veriden yararlanılarak antosiyanin içeriğinin açıklanabilmesi bakımından kalibrasyon setinde yaklaşık 6 kat, dış doğrulama setinde ise 9 kat daha artış olduğunu söylemek mümkündür (Tablo 3). Tüm spektral veriye önişlem uygulanmasının tahmin başarısını dikkate değer şekilde artırdığı görülse de, dalga boyu seçim yöntemi uygulanması halinde modele ilişkin tahmin gücünün yükseldiği görülmektedir.

Antosiyanin içeriğinin mısır tanesinde NIR spektroskopisi tespitine yönelik bir araştırmada (Mangalvedhe vd., 2015) oluşturulan kalibrasyon modeline ait $R^{2}$ değeri 0.72 dış doğrulama setine ilişkin $R^{2}$ ise 0.93 olarak 
hesaplanmıştır. Araştırmamızda geliştirilen modellerden kalibrasyon seti için benzer sonuçlara ulaşılmış ancak dış doğrulamaya ilişkin $\mathrm{R}^{2}$ değerleri bu çalışmadan daha düşük bulunmuştur. $\mathrm{Bu}$ durumun başlıca nedeni kullanılan örneklerdeki antosiyanin miktarındaki değişmeler ve kullanılan spektroskopi cihazlarındaki farklılıklardır. Mangalvedhe vd. (2015) tarafında yürütülen araştırmada 0-900 mg/kg'lık geniş bir varyasyon var iken, kullanılan cihaz ise 900-1650 nm arasını taramaktadır. Araştırmamızda ise antosiyanin içeriğine ilişkin varyasyon daha düşük olmakla birlikte kullanılan cihazın tarama aralığ $(2100-2400 \mathrm{~nm})$ daha geniştir. Antosiyanin içeriği için spektral veriye ön işlem uygulanması halinde ölçüm başarısının arttığı gözlenmiş̧ir. Kemometrik yöntem uygulamalarının spektral model başarısına olumlu yönde etki ettiğini gösteren farklı çalışmalar vardır (Alfieri vd. 2019; Kahriman, 2017). Çalışmamızdan elde edilen sonuçlar da bu bulguları doğrular niteliktedir.
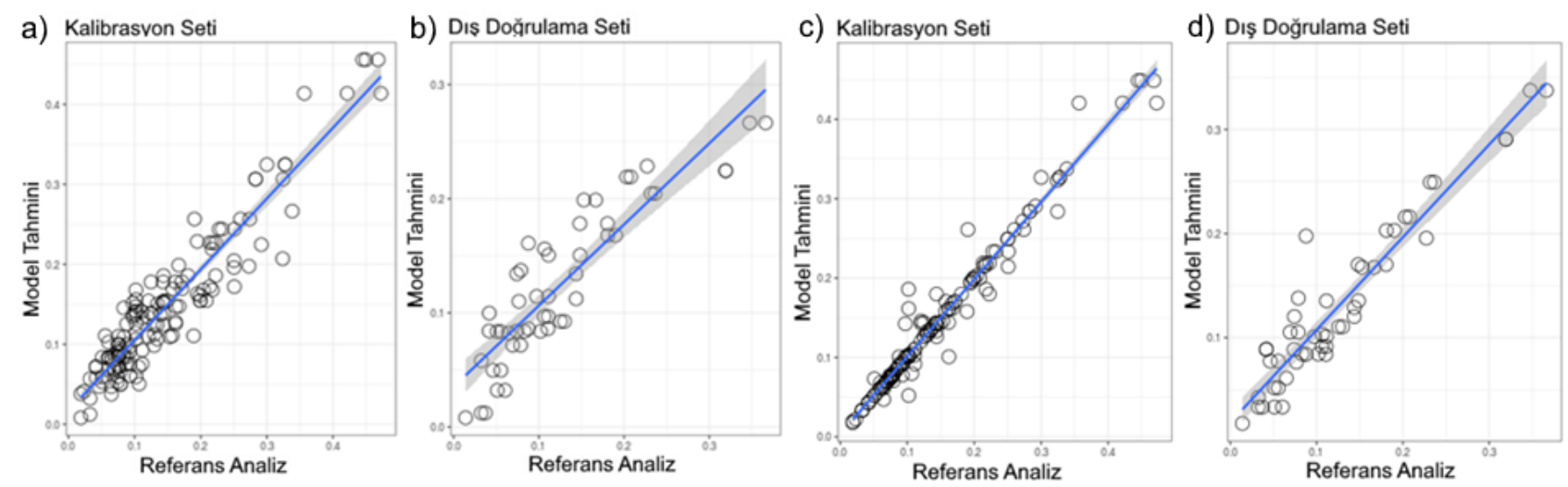

Şekil 1. Antosiyanin içeriği için PLS yönteminde (a, b) ve SVM yönteminde (c, d) en iyi tahmin sonucu veren kalibrasyon ve dış doğrulama setlerine ait tahmin grafikleri

Tablo 3.

Toplam antosiyanin içeriğine yönelik NIR tahmin modellerine ait değerlendirme istatistikleri

\begin{tabular}{lllllllll} 
Önişlem & Seçim Yöntemi & RM & RMSE $_{\text {Cal }}$ & $\mathrm{R}^{2}$ Cal & RPD $_{\text {Cal }}$ & RMSE $_{\text {Val }}$ & $\mathrm{R}^{2}{ }_{\text {Val }}$ & RPD $_{\text {Val }}$ \\
\hline Ön İşlemsiz & Tüm Spektrum & PLS & 0.09 & 0.15 & 1.09 & 0.09 & 0.10 & 1.06 \\
FD & Tüm Spektrum & PLS & 0.04 & 0.85 & 2.66 & 0.05 & 0.70 & 1.85 \\
SD & Tüm Spektrum & PLS & 0.04 & 0.82 & 2.37 & 0.06 & 0.65 & 1.71 \\
SNV & Tüm Spektrum & PLS & 0.03 & 0.88 & 2.92 & 0.05 & 0.69 & 1.83 \\
FD+SNV & Tüm Spektrum & PLS & 0.06 & 0.58 & 1.55 & 0.07 & 0.48 & 1.40 \\
SD+SNV & Tüm Spektrum & PLS & 0.04 & 0.82 & 2.38 & 0.06 & 0.64 & 1.68 \\
Ön İşlemsiz & VIP & PLS & 0.09 & 0.15 & 1.09 & 0.09 & 0.10 & 1.06 \\
FD & VIP & PLS & 0.04 & 0.85 & 2.61 & 0.05 & 0.72 & 1.91 \\
SD & VIP & PLS & 0.04 & 0.82 & 2.37 & 0.05 & 0.68 & 1.79 \\
SNV & VIP & PLS & 0.03 & 0.87 & 2.88 & 0.05 & 0.74 & 1.97 \\
FD+SNV & VIP & PLS & 0.03 & 0.86 & 2.72 & 0.05 & 0.71 & 1.88 \\
SD+SNV & VIP & PLS & 0.05 & 0.75 & 2.03 & 0.06 & 0.62 & 1.64 \\
Ön İşlemsiz & SR & PLS & 0.09 & 0.15 & 1.09 & 0.09 & 0.10 & 1.06 \\
FD & SR & PLS & 0.04 & 0.85 & 2.65 & 0.05 & 0.70 & 1.83 \\
\hline
\end{tabular}

FD: Birinci türev; SD: İkinci türev; SNV: Standart normal değişim; RM: Regresyon metodu; VIP: Değişken önemlilik projeksiyonu; SR: Seçicilik oranı. 
Tablo 3 (devami).

Toplam antosiyanin içeriğine yönelik NIR tahmin modellerine ait değerlendirme istatistikleri

\begin{tabular}{|c|c|c|c|c|c|c|c|c|}
\hline Önişlem & Seçim Yöntemi & $\mathrm{RM}$ & $\mathrm{RMSE}_{\mathrm{Cal}}$ & $\mathrm{R}^{2} \mathrm{Cal}$ & $\mathrm{RPD}_{\mathrm{Cal}}$ & $\mathrm{RMSE}_{\text {Val }}$ & $\mathrm{R}^{2}$ Val & $\mathrm{RPD}_{\text {Val }}$ \\
\hline SD & SR & PLS & 0.04 & 0.82 & 2.37 & 0.06 & 0.65 & 1.71 \\
\hline SNV & SR & PLS & 0.07 & 0.51 & 1.43 & 0.07 & 0.40 & 1.30 \\
\hline $\mathrm{FD}+\mathrm{SNV}$ & SR & PLS & 0.06 & 0.57 & 1.53 & 0.07 & 0.47 & 1.39 \\
\hline $\mathrm{SD}+\mathrm{SNV}$ & SR & PLS & 0.04 & 0.81 & 2.36 & 0.06 & 0.63 & 1.66 \\
\hline Ön işlemsiz & Tüm Spektrum & SVM & 0.04 & 0.82 & 2.39 & 0.05 & 0.64 & 1.69 \\
\hline FD & Tüm Spektrum & SVM & 0.02 & 0.97 & 5.47 & 0.03 & 0.88 & 2.93 \\
\hline SD & Tüm Spektrum & SVM & 0.02 & 0.96 & 5.27 & 0.03 & 0.88 & 2.93 \\
\hline SNV & Tüm Spektrum & SVM & 0.02 & 0.96 & 5.16 & 0.03 & 0.88 & 2.92 \\
\hline $\mathrm{FD}+\mathrm{SNV}$ & Tüm Spektrum & SVM & 0.02 & 0.97 & 5.39 & 0.03 & 0.88 & 2.92 \\
\hline $\mathrm{SD}+\mathrm{SNV}$ & Tüm Spektrum & SVM & 0.02 & 0.96 & 5.21 & 0.03 & 0.88 & 2.94 \\
\hline Ön İşlemsiz & VIP & SVM & 0.10 & 0.10 & 0.96 & 0.08 & 0.20 & 1.00 \\
\hline FD & VIP & SVM & 0.02 & 0.97 & 5.37 & 0.03 & 0.89 & 3.09 \\
\hline SD & VIP & SVM & 0.02 & 0.97 & 5.50 & 0.03 & 0.89 & 3.11 \\
\hline SNV & VIP & SVM & 0.03 & 0.89 & 2.99 & 0.04 & 0.72 & 1.92 \\
\hline $\mathrm{FD}+\mathrm{SNV}$ & VIP & SVM & 0.02 & 0.96 & 4.85 & 0.03 & 0.89 & 3.09 \\
\hline $\mathrm{SD}+\mathrm{SNV}$ & VIP & SVM & 0.02 & 0.97 & 5.46 & 0.03 & 0.90 & 3.13 \\
\hline Ön İşlemsiz & SR & SVM & 0.10 & 0.10 & 0.96 & 0.08 & 0.20 & 1.00 \\
\hline FD & SR & SVM & 0.02 & 0.97 & 5.54 & 0.03 & 0.89 & 3.10 \\
\hline SD & SR & SVM & 0.02 & 0.97 & 5.48 & 0.03 & 0.89 & 3.12 \\
\hline SNV & SR & SVM & 0.03 & 0.90 & 3.12 & 0.04 & 0.80 & 2.25 \\
\hline $\mathrm{FD}+\mathrm{SNV}$ & SR & SVM & 0.02 & 0.96 & 5.36 & 0.03 & 0.90 & 3.14 \\
\hline $\mathrm{SD}+\mathrm{SNV}$ & SR & SVM & 0.02 & 0.97 & 5.42 & 0.03 & 0.90 & 3.13 \\
\hline
\end{tabular}

FD: Birinci türev; SD: İkinci türev; SNV: Standart normal değişim; RM: Regresyon metodu; VIP: Değişken önemlilik projeksiyonu; SR: Seçicilik oranı.

Toplam fenolik içeriği için oluşturulan PLS ve SVM model değerlendirme sonuçları ise Tablo 4'de gösterilmiştir. Kullanılan her iki modelleme tekniğinde de ön işlemsiz spektral verinin VIP dalga boyu seçim yöntemine uygulanması ile oluşturulan modellerin, diğerlerinden daha başarılı sonuç verdiği gözlenmiştir. Bu modelere ait değerlendirme istatistikleri birbiri ile kıyaslandığında ise PLS tekniğinde başarılı bulunan ve ön işlem uygulanmadan VIP dalga boyu seçimi yapılan modelin $\left(\mathrm{RMSE}_{\mathrm{Cal}}=0.05, \mathrm{R}_{\mathrm{Cal}}^{2}=0.71, \mathrm{RPD}_{\mathrm{Cal}}=1.87\right.$, $\left.\mathrm{RMSE}_{\mathrm{Val}}=0.06, \mathrm{R}_{\mathrm{Val}}^{2}=0.66, \mathrm{RPD}_{\mathrm{Val}}=1.72\right) \mathrm{SVM}$ tekniğinde başarılı bulunan ve ön işlem uygulanmadan VIP dalga boyu seçimi yapilan modelden $\left(\mathrm{RMSE}_{\mathrm{Cal}}=0.06, \mathrm{R}_{\mathrm{Cal}}=0.66, \mathrm{RPD}_{\mathrm{Cal}}=1.71, \mathrm{RMSE}_{\mathrm{Val}}=0.07, \mathrm{R}^{2} \mathrm{Val}=0.46\right.$, $\mathrm{RPD}_{\mathrm{Val}}=1.38$ ) nispeten daha başarılı sonuç verdiği izlenmektedir (Tablo 4, Şekil 2). Ancak toplam fenolik içeriği için oluşturulan bu modellerin RPD değerlerine göre modellerin orta düzeyde $(1.4<\mathrm{RPD}<2)$ güvenilirliğe sahip olduğu anlaşılmaktadır.

Meng vd. (2015) öğütülmemiş ve öğütülmüş mısır tanesi numunelerinde fenolik bileşen tespitine yönelik geliştirdikleri NIR kalibrasyon modellerinde $\mathrm{R}^{2}$ değeri \%90'ın üzerinde olan modellerin olduğunu bildirmişlerdir. Mevcut çalışmada geliştirilmiş modellerin $\mathrm{R}^{2}$ değerleri Meng vd (2015) tarafından çalışmada geliştirilmiş modellerden düşük bulunmuştur. Bu durumun başlıca nedenlerinden birisi kullanılan örnek setinin fenolik madde içeriği bakımından çok büyük bir değişime sahip olmasıdır. Araştırmamızda bu biyokimyasal 
bileşen için tespit edilen sınır değerler nispeten dar bulunmuştur. Bu durum geliştirilen kalibrasyon modellerinin değerlendirme istatistiklerine yansımıştır.

Tablo 4.

Toplam fenolik içeriğine yönelik NIR tahmin modellerine ait değerlendirme istatistikleri

\begin{tabular}{|c|c|c|c|c|c|c|c|c|}
\hline Ön İşlem & Seçim Yöntemi & $\mathrm{RM}$ & $\mathrm{RMSE}_{\mathrm{Cal}}$ & $\mathrm{R}^{2}{ }_{\mathrm{Cal}}$ & $\mathrm{RPD}_{\text {Cal }}$ & $\mathrm{RMSE}_{\mathrm{Val}}$ & $\mathrm{R}_{\text {Val }}^{2}$ & $\mathrm{RPD}_{\text {Val }}$ \\
\hline Ön İşlemsiz & Tüm Spektrum & PLS & 0.05 & 0.71 & 1.87 & 0.06 & 0.65 & 1.71 \\
\hline FD & Tüm Spektrum & PLS & 0.06 & 0.67 & 1.75 & 0.06 & 0.60 & 1.60 \\
\hline $\mathrm{SD}$ & Tüm Spektrum & PLS & 0.05 & 0.72 & 1.91 & 0.07 & 0.48 & 1.40 \\
\hline SNV & Tüm Spektrum & PLS & 0.06 & 0.67 & 1.77 & 0.06 & 0.60 & 1.60 \\
\hline $\mathrm{FD}+\mathrm{SNV}$ & Tüm Spektrum & PLS & 0.06 & 0.66 & 1.73 & 0.06 & 0.60 & 1.59 \\
\hline $\mathrm{SD}+\mathrm{SNV}$ & Tüm Spektrum & PLS & 0.06 & 0.62 & 1.64 & 0.07 & 0.45 & 1.36 \\
\hline Ön İşlemsiz & VIP & PLS & 0.05 & 0.71 & 1.87 & 0.06 & 0.66 & 1.72 \\
\hline FD & VIP & PLS & 0.06 & 0.67 & 1.75 & 0.06 & 0.60 & 1.61 \\
\hline SD & VIP & PLS & 0.04 & 0.83 & 2.45 & 0.07 & 0.55 & 1.50 \\
\hline SNV & VIP & PLS & 0.06 & 0.68 & 1.78 & 0.06 & 0.61 & 1.62 \\
\hline $\mathrm{FD}+\mathrm{SNV}$ & VIP & PLS & 0.06 & 0.66 & 1.74 & 0.06 & 0.60 & 1.61 \\
\hline $\mathrm{SD}+\mathrm{SNV}$ & VIP & PLS & 0.04 & 0.80 & 2.25 & 0.07 & 0.53 & 1.48 \\
\hline Ön İşlemsiz & SR & PLS & 0.05 & 0.71 & 1.87 & 0.06 & 0.65 & 1.71 \\
\hline FD & SR & PLS & 0.06 & 0.67 & 1.75 & 0.06 & 0.60 & 1.60 \\
\hline SD & SR & PLS & 0.05 & 0.72 & 1.91 & 0.07 & 0.47 & 1.39 \\
\hline SNV & SR & PLS & 0.06 & 0.67 & 1.77 & 0.06 & 0.60 & 1.60 \\
\hline $\mathrm{FD}+\mathrm{SNV}$ & SR & PLS & 0.06 & 0.66 & 1.73 & 0.06 & 0.60 & 1.59 \\
\hline $\mathrm{SD}+\mathrm{SNV}$ & SR & PLS & 0.06 & 0.62 & 1.64 & 0.07 & 0.45 & 1.36 \\
\hline Ön İşlemsiz & Tüm Spektrum & SVM & 0.04 & 0.83 & 2.44 & 0.09 & 0.34 & 1.25 \\
\hline FD & Tüm Spektrum & SVM & 0.01 & 0.99 & 12.21 & 0.09 & 0.43 & 1.34 \\
\hline SD & Tüm Spektrum & SVM & 0.01 & 0.99 & 10.95 & 0.09 & 0.43 & 1.34 \\
\hline SNV & Tüm Spektrum & SVM & 0.01 & 0.99 & 11.59 & 0.09 & 0.43 & 1.34 \\
\hline $\mathrm{FD}+\mathrm{SNV}$ & Tüm Spektrum & SVM & 0.01 & 0.99 & 13.92 & 0.09 & 0.43 & 1.34 \\
\hline $\mathrm{SD}+\mathrm{SNV}$ & Tüm Spektrum & SVM & 0.01 & 0.99 & 12.21 & 0.09 & 0.43 & 1.34 \\
\hline Ön İşlemsiz & VIP & SVM & 0.06 & 0.66 & 1.71 & 0.07 & 0.46 & 1.38 \\
\hline FD & VIP & SVM & 0.02 & 0.95 & 4.41 & 0.08 & 0.31 & 1.22 \\
\hline $\mathrm{SD}$ & VIP & SVM & 0.01 & 0.99 & 12.54 & 0.09 & 0.22 & 1.14 \\
\hline SNV & VIP & SVM & 0.05 & 0.79 & 2.19 & 0.07 & 0.45 & 1.37 \\
\hline $\mathrm{FD}+\mathrm{SNV}$ & VIP & SVM & 0.03 & 0.88 & 2.89 & 0.07 & 0.43 & 1.34 \\
\hline $\mathrm{SD}+\mathrm{SNV}$ & VIP & SVM & 0.01 & 0.99 & 9.36 & 0.09 & 0.22 & 1.15 \\
\hline
\end{tabular}

FD: Birinci türev; SD: İkinci türev; SNV: Standart normal değişim; RM: Regresyon metodu; VIP: Değişken önemlilik projeksiyonu; SR: Seçicilik oranı. 
Tablo 4 (devami).

Toplam fenolik içeriğine yönelik NIR tahmin modellerine ait değerlendirme istatistikleri

\begin{tabular}{lllllllll}
\hline Ön İşlem & Seçim Yöntemi & RM & RMSE $_{\text {Cal }}$ & $R^{2}$ Cal & $R_{\text {RPal }}$ & $R_{M S E}$ Val & $R^{2}$ Val & $R^{2} D_{\text {Val }}$ \\
Ön İşlemsiz & SR & SVM & 0.10 & 0.20 & 1.00 & 0.10 & 0.10 & 1.00 \\
FD & SR & SVM & 0.01 & 0.99 & 8.55 & 0.08 & 0.28 & 1.19 \\
SD & SR & SVM & 0.01 & 0.99 & 10.99 & 0.09 & 0.22 & 1.15 \\
SNV & SR & SVM & 0.04 & 0.83 & 2.43 & 0.07 & 0.43 & 1.33 \\
FD+SNV & SR & SVM & 0.02 & 0.98 & 6.36 & 0.08 & 0.33 & 1.23 \\
SD+SNV & SR & SVM & 0.01 & 0.99 & 11.84 & 0.09 & 0.22 & 1.14 \\
\hline
\end{tabular}

FD: Birinci türev; SD: İkinci türev; SNV: Standart normal değişim; RM: Regresyon metodu; VIP: Değişken önemlilik projeksiyonu; SR: Seçicilik oranı.
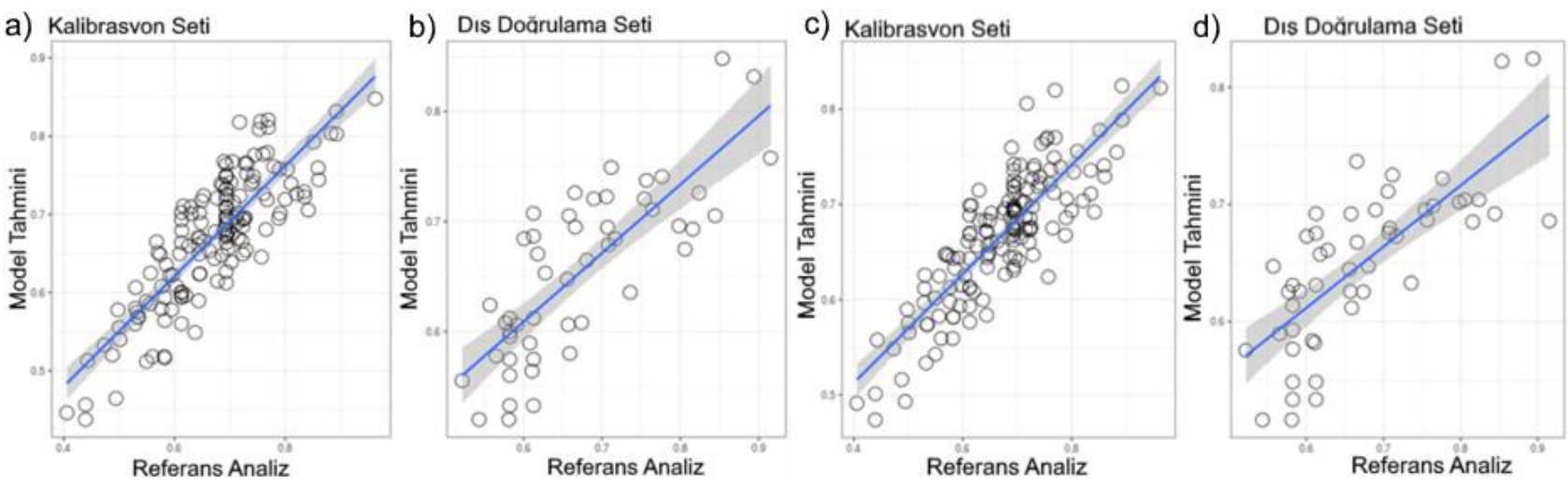

Şekil 2. Fenolik bileşen içeriği için PLS yönteminde (a, b) ve SVM yönteminde (c, d) en iyi tahmin sonucu veren kalibrasyon ve diş doğrulama setlerine ait tahmin grafikleri

\subsection{Modellerde Etkili Dalga Boyları}

Elektromanyetik spektrumda NIR bölgesindeki dalga boylarının 1şık enerjisi ile etkileşimi komplike bir yapıdadır. Maddelerin yapısında bulunan $\mathrm{C}-\mathrm{H}, \mathrm{O}-\mathrm{H}, \mathrm{N}-\mathrm{H}$ ve $\mathrm{S}-\mathrm{H}$ gibi kimyasal bağların ışık ile etkileşimi sonucunda bu bağlar esneme, bükülme gibi hareketler yapmaktadır (Pasquini, 2003). NIR spektroskopisinde, elektromanyetik spektrumda temel yakın kızıl ötesi bölgesi (750-2500) ile organik bileşenlerin yapısındaki alifatik ve aromatik $(\mathrm{C}-\mathrm{H})$, karboksil $(\mathrm{C}-\mathrm{O})$, hidroksil $(\mathrm{O}-\mathrm{H})$ ve amin-amid $(\mathrm{N}-\mathrm{H})$ bağlarının enerji düzeylerindeki değişimin ölçülmesine dayanmaktadır (Williams ve Norris, 1987). Fenolik bileşenler ve antosiyaninler temel olarak $\mathrm{C}-\mathrm{H}, \mathrm{O}-\mathrm{H}$ bağları bulunduran biyokimyasal bileşenlerdir. Bu bağ yapıları genel olarak fenolik maddelerle ilişkilendirilmektedir (Nicolaï vd., 2007).

Antosiyanin içeriği için oluşturulan PLS ve SVM modellerinde etkili bulunan dalga boylarını gösteren grafik Şekil 3'te gösterilmiştir. Modelleme tekniğine göre etkili bulunan dalga boylarının değişim gösterdiği anlaşılmaktadır. PLS modelinde etkili bulunan dalga boyu sayısı SVM modelinden daha az sayıdadır. PLS modelinde etkili dalga boyları $1200 \mathrm{~nm}, 1400 \mathrm{~nm}, 1700 \mathrm{~nm}$ ve 1900-2400 nm arasındaki bölgelerde yer almıştır (Şekil 3a). SVM modelinde $1750 \mathrm{~nm}$ ve $2050 \mathrm{~nm}$ 'ye yakın bölgeler dışında kalan bölgelerdeki dalga boylarının tahminleyici olarak yer aldığı görülmektedir (Şekil 3b). Mariani vd. (2015) bitkisel örneklerde antosiyanin içeriğinin NIR spektral bölgesinde yer alan 1232-1279 nm, 1319-1522 nm, 1792-2009 nm ve 2245-2387 nm dalga boylarında oluştuğunu bildirmişlerdir. Antosiyaninlerin kimyasal yapısı dikkate alındığında hidroksil grubun birinci overton bölgesi 1400-1600 nm arası bölge ile etkileşimde olduğu, C-O ve O-H bağlarının deformasyon bölgesi olan $2100 \mathrm{~nm}$ ve O-H, C-C bağlarının kombinasyon bant bölgesi olan 2276 nm'ye yakın bölgeler de antosiyaninlerle ilişkili olduğu bildirilmiştir (Noah vd., 1997). Antosiyaninler suda çözünebilen bileşenlerdir bu sebeple örnek içerisindeki nem içeriği ile ilişki olan dalga boylarının da 
dikkate alınmasında yarar vardır. Su ile NIR bölgesinde ilişkili olduğu bilinen bantlar 760, 970, 1190, 1450 ve $1940 \mathrm{~nm}$ dalga boylarıdır (Paulsen ve Singh, 1994). Çalışmamızda tarama yapılan bölgede (1200-2400 nm) su ile ilişkili bulunan dalga boylarının da tahmin modellerinde yer aldığı görülmektedir. Bu durum antosiyanin miktarının söz konusu bantlar tarafından maskelenmesine neden olabilir ve başarılı bulunan modellerde söz konusu bölgelerin elemine edildiği görülmektedir.

a)

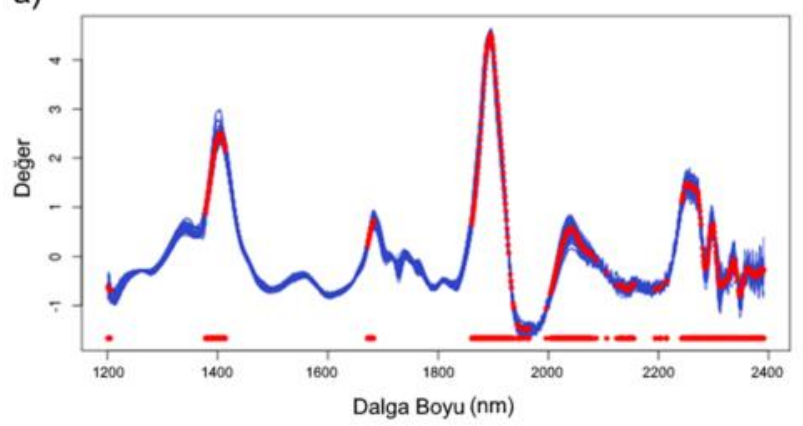

b)

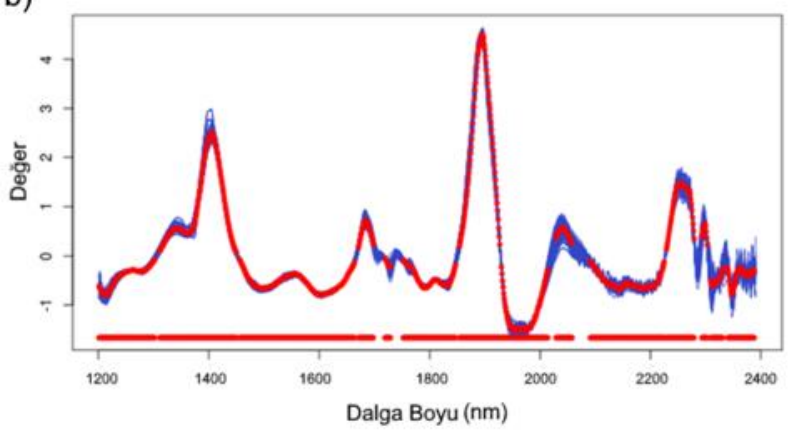

Şekil 3. Antosiyanin için en iyi tahmin sonucu veren PLS (a) ve SVM (b) modellerde etkili bulunan dalga boylarını gösteren grafikler

Fenolik bileşenlerin tespitinde PLS ve SVM yöntemlerinde başarılı bulunan modeller için taranan spektral aralıkta (1200-2400 nm) aynı bölgelerin etkili olduğu saptanmıştır (Şekil 4). Oluşturulan PLS ve SVM yöntemi için $1200 \mathrm{~nm}, 1500 \mathrm{~nm}, 1800 \mathrm{~nm}, 2100 \mathrm{~nm}$ ve $2200 \mathrm{~nm}$ bölgelerindeki dalga boylarının etkili olduğu görülmektedir (Şekil 4). Literatürde fenolik bileşenlerin NIR spektral bölgesinde farklı bölgelerle ilgili olduğu rapor edilmiştir. Miller (2001) NIR spektrumunda 1415 nm'den 1512 nm'ye ve 1955 nm'den 2035 nm'ye kadar olan bölgelerin fenolik bileşenlerle ilgili karakteristik bantlar bulundurduğunu rapor etmiştir. Diğer fonksiyonel bağ tepkileri içerisinde, O-H hidroksil grubu $(1514 \mathrm{~nm}), \mathrm{C}-\mathrm{O}$ bağlarının etkili olduğu $2056 \mathrm{~nm}$ ve C-H bağlarının birinci overtone bölgesindeki $1762 \mathrm{~nm}, 2142 \mathrm{~nm}$ ve $2170 \mathrm{~nm}$ 'deki dalga boylarının fenolik bileşenlerle ilişkili olduğu bildirilmiştir (Osborne, 1993). Sorgumda yürütülen bir çalışmada 400-2500 nm arasında taranan spektral aralıkta $508 \mathrm{~nm}, 608 \mathrm{~nm}, 114 \mathrm{~nm}, 1304 \mathrm{~nm}, 1680 \mathrm{~nm}, 1904 \mathrm{~nm}, 2104 \mathrm{~nm}, 2230 \mathrm{~nm}$ ve $2244 \mathrm{~nm}$ dalga boylarının tahmin modellerinde etkili olduğu bildirilmiştir (Alfieri vd., 2019). Çalışmamızda fenolik bileşenlere yönelik modellerde etkili bulunan bölgeler bilimsel çalışmalardaki söz konusu spektral aralıkları içermektedir.
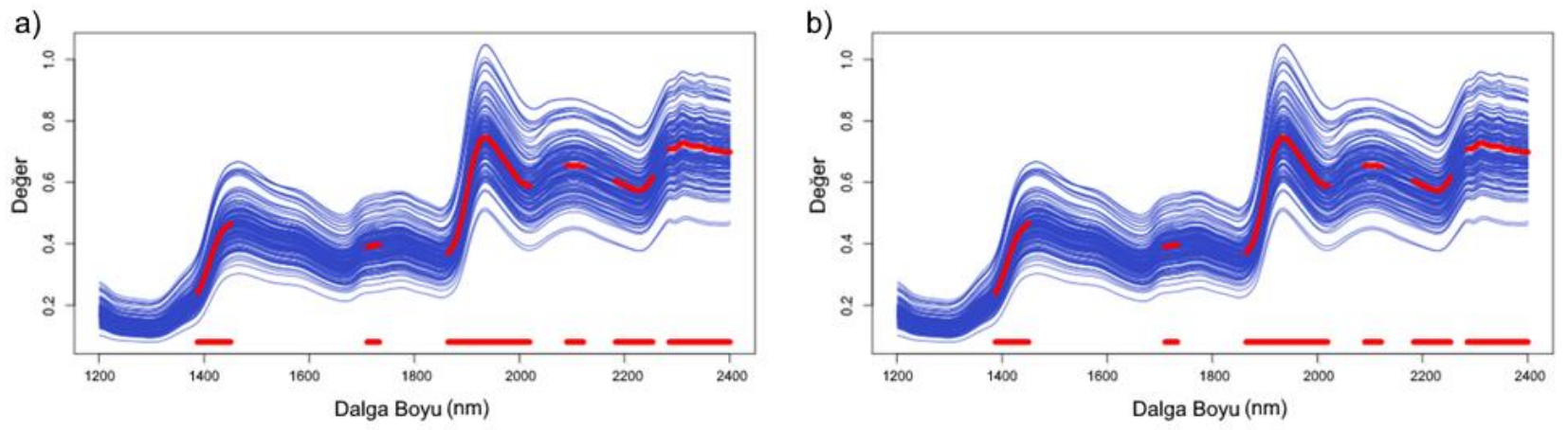

Şekil 4. Fenolik bileşenler için en iyi tahmin sonucu veren PLS (a) ve SVM (b) modellerde etkili bulunan dalga boylarını gösteren grafikler 


\section{Sonuçlar}

Mısır örneklerinde toplam antosiyanin ve fenolik içeriğinin tespitinde NIR spektroskopisi cihazından yararlanılabileceği görülmüştür. $\mathrm{Bu}$ cihazda geliştirilen kalibrasyon modellerinde kullanılan kemometrik yöntemlerin model başarısına önemli etkisi olduğu anlaşılmıştır. Araştırmada her özellik için geliştirilen 36 ayrı modelden başarılı bulunan modellerin spektral önişlem ve dalga boyu seçim yöntemlerinin kullanıldığı modeller olduğu dikkat çekmiştir. Antosiyanin içeriği için FD+SNV+SR kombinasyonu ile SVM modelleme yöntemi oluşturulan modelin tahmin başarısının diğer modellerden daha yüksek olduğu gözlenmiştir. Toplam fenolik bileşen için ön işlem uygulanmadan VIP dalga boyu seçim yöntemi diğer kombinasyonlardan daha yüksek başarı sağlasa da, bu modellerin tahmin güvenilirlikleri orta düzeyde kalmıştır. Antosiyanin içeriği için PLS ve SVM modelleme yöntemlerinde farklı dalga boylarının etkili olduğu görülmüş ve SVM yönteminde tarama yapılan spektral aralıkta daha fazla sayıda bölge tahmin modeline dahil olmuştur. Buna karşın toplam fenolik içeriği için ise her iki modelleme yönteminde de etkili dalga boylarının aynı olduğu görülmüştür. İleride bu bileşenlere yönelik çalışmalarda farklı kemometrik yöntemlerin de kullanılması faydalı olacaktır. Kullanılacak örnek setinde hedef değişkenler bakımından varyasyonun örnek sayısı ve biyokimyasal içerik bakımından değişimin artırılması da model başarısını olumlu yönde etkileyebilir. Antosiyanin ve fenolik bileşenlerin yanı sıra diğer sekonder metabolitlerin NIR ile tespitinde kemometrik yöntemlerin etkisine yönelik çalışmalar da yapılmalıdır.

\section{Teşekkür}

Bu makale Ziraat Yüksek Mühendisi Mehmet Şerment'in yüksek lisans tez çalışmasından derlenmiştir. Bu çalışma Çanakkale Onsekiz Mart Üniversitesi Bilimsel Araştırma Projeleri Koordinasyon Birimince Desteklenmiştir. Proje Numarası: FYL-2018-2754.

\section{Yazar Katkıları}

Mehmet Şerment: Laboratuvar analizlerini yapmış ve makaleyi yazmıştır.

Fatih Kahrıman: Çalışmayı planlamış, istatistik analizleri yapmış ve makale yazımına katkı sunmuştur.

\section{Çıkar Çatışması}

Yazarlar çıkar çatışması bildirmemişlerdir.

\section{Kaynaklar}

Abdel-Aal, E.S.M. ve Hucl, P. (1999). A rapid method for quantifying total anthocyanins in blue aleurone and purple pericarp wheats. Cereal Chemistry, 76, 350-354. https://doi.org/10.1094/CCHEM.1999.76.3.350

Adom, K.K. ve Liu, R.H. (2002). Antioxidant activity of grains. Journal of Agricultural and Food Chemistry, 50: 6182-6187. https://doi.org/10.1021/jf0205099

Agelet, L.E., Hurburgh Jr., C.R. (2010). A tutorial on near infrared spectroscopy and its calibration. Critical Reviews in Analytical Chemistry, 40:4, 246-260. https://doi.org/10.1080/10408347.2010.515468

Alfieri, M., Cabassi, G., Habyarimana, E., Quaranta, F., Balconi, C. ve Redaelli, R. (2019). Discrimination and prediction of polyphenolic compounds and total antioxidant capacity in sorghum grains. Journal of Near Infrared Spectroscopy, 27(1):46-53. https://doi.org/10.1177/0967033518825351

Baye, T.M., Pearson T.C. ve Settles A.M. (2006). Development of a calibration to predict maize seed composition using single kernel near infrared spectroscopy. Journal of Cereal Science, 43(2): 236-243. https://doi.org/10.1016/j.jcs.2005.11.003

Egesel C.Ö. ve Kahriman F. (2012). Determination of quality parameters in maize by nir reflectance spectroscopy. Journal of Agricultural Sicences, 18:43-53. https://doi.org/10.1501/tarimbil_0000001190

Egesel C.Ö. Kahriman F. Ekinci N. Kavdir İ.ve Büyükcan M.B. (2016). Analysis of fatty acids in kernel, flour and oil samples of maize by NIR spectroscopy using conventional regression methods. Cereal Chemistry, 93:487-492. https://doi.org/10.1094/cchem-12-15-0247-r

Galicia, L., Nurit, E., Rosales, A.ve Palacios-Rojas, N. (2009). Laboratory protocols (2008): Maize nutrition 
quality and plant tissue analysis laboratory. CIMMYT, 42. Erişim adresi: https://repository.cimmyt.org/bitstream/handle/10883/804/91513.pdf?sequence=1\&isAllowed $=\mathrm{y}$

Ji, H.C., Lee, H.B. ve Takeo, Y. (2010). Major agricultural characteristics and antioxidants analysis of the new developed colored waxy corn hybrids. Journal of the Faculty of Agriculture, Kyushu University, 55(1): 55-59. https://doi.org/10.5109/17800

Jing, P. ve Giusti, M. M. (2005). Characterization of anthocyanin-rich waste from purple corn cobs (Zea mays L.) and its application to color milk. Journal of Agricultural and Food Chemistry, 53: 8775-8781. https://doi.org/10.1021/jf051247o

Kahriman F., (2017). Mısır yağında yağ asitlerinin uv-vis spektroskopisi ve kemometrik yöntemler yardımıyla tespit edilmesi. Journal of Food And Health Science, 3:82-89. https://doi.org/10.3153/jfhs17011

Kahriman, F., Öner, F., Türk, F., Gökçe, A., Düzen, E., Onaç, İ. ve Egesel C.Ö. (2017). Efficiency of different chemometric methods for determination of oil content in maize by nir spectroscopy, AGROSYM (2017), Jahorina, Bosnia and Herzegovina, 5-8 October 2017. Erişim adresi: https://www.cabdirect.org/cabdirect/FullTextPDF/2018/20183050244.pdf

Kahrıman, F. ve Egesel C.Ö. (2018). Using near infrared (NIR) spectroscopy in the analysis of cereal products: the example of maize, In: Recent researches in science and landscape management, Ed: Prof. Dr. Recep Efe, (pp. 560-574).

Kahriman, F., Onaç, İ., Mert F., Öner F.ve Egesel, C.Ö., (2019). Determination of carotenoid and tocopherol content in maize flour and oil samples using near-infrared spectroscopy. Spectroscopy Letters, 52, 473481. https://doi.org/10.1080/00387010.2019.1671872

Kahriman, F., Onaç, İ., Öner, F., Mert-Turk, F. ve Egesel C.Ö. (2020). Analysis of secondary biochemical components in maize flour samples by NIR (near infrared reflectance) spectroscopy. Journal of Food Measurement and Characterization, 14:2320-2332. https://doi.org/10.1007/s11694-020-00479-0

Kahrıman, F. ve Liland, K-H. (2021). SelectWave: a graphical user interface for spectral data analysis. $\begin{array}{llll}\text { Chemometrics and Intelligent Laboratory } & \text { Systems, }\end{array}$ https://doi.org/10.1016/j.chemolab.2021.104275

Keleş, Y. (2015). Antosiyanin pigmentlerin biyokimyası ve analizi, Türk Bilimsel Derlemeler Dergisi, 8 (1): $19-25$.

Lago, C., Cassani, E., Zanzi, C., ve Pilu R. (2014). Development and study of a maize cultivar rich in anthocyanins: coloured polenta, a new functional food. Plant Breeding, 133(2):210-217. https://doi.org/10.1111/pbr.12153

Lao, C., Zhang, Z., Chen, J., Chen, H., Yao, Z., Xing, Z., Tai, X., Ning, J., Chen, Y. (2020). Determination of in-situ salinized soil moisture content from visible-near infrared (VIS-NIR) spectroscopy by fractional order derivative and spectral variable selection algorithms. International Journal of Precision Agricultural Aviation, 3(3):21-34. https://doi.org/10.33440/j.ijpaa.20200303.98

Lopez-Martinez, L.X., Oliart-Ros, R.M., Valerio-Alfaro, G., Lee, C.H., Parkin, K.L. ve Garcia, H.S. (2009). Antioxidant activity, phenolic compounds and anthocyanins content of eighteen strains of Mexican maize. LWT-Food Science and Technology, 42:1187-92. https://doi.org/10.1016/j.lwt.2008.10.010

Mangalvedhe, A.A., Danao, M.C., Paulsmeyer, M., Rausch, K.D., Singh, V.ve Juvik, J.A. (2015). Anthocyanin determination in different corn hybrids using near infrared spectroscopy. ASABE Annual International Meeting, New Orleans. Paper Number: 152181716.

Mariani, N.C.T., Teixeira, G.H.A., Lima, K.M.G., Morgenstern, T.B., Nardini, V. ve Cunha, L.C. (2015). NIRS and iSPA-PLS for predicting total anthocyanin content in jaboticaba fruit. Journal of Food Chemistry, 174: 643-648. https://doi.org/10.1016/j.foodchem.2014.11.008

Meng, Q., Murray, S.C., Mahan, A., Collison, A., Yang, L. ve Awika, J. (2015). Rapid estimation of phenolic content in colored maize by near-infrared reflectance spectroscopy and its use in breeding. Crop Science, 55: 2234-2243. https://doi.org/10.2135/cropsci2014.11.0767

Miller C.E. (2001). Chemical principles of near-infrared technology. In: Williams P.C., Norris K.H., editors. Near-Infrared Technology in the Agricultural and Food Industries. 2nd ed. American Association of Cereal Chemists; St. Paul, MN, USA.

Nicolaï, B.M., Beullens, K., Bobelyn, E., Peirs, A., Saeys, W., Theron, K.I. ve Lammertyn, J. (2007). 
Nondestructive measurement of fruit and vegetable quality by means of NIR spectroscopy: a review. Postharvest Biology and Technology, 46:99-118. https://doi.org/10.1016/j.postharvbio.2007.06.024

Noah, L., Robert, P., Millar, S. ve Champ, M. (1997). Near-infrared spectroscopy as applied to starch analysis of digestive contents. Journal of Agricultural and Food Chemistry, 45: 2593-2597. https://doi.org/10.1021/jf960891n

Osborne B.G., Fearn T. ve Hindle P. (1993). Practical nir spectroscopy with applications in food and beverage analysis. Longman Scientific and Technical; London, UK: 1993.

Pasquini, C., (2003). Near infrared spectroscopy:Fundamentals, practical aspects and analytical applications. Journal of the Brazilian Chemical Society,14(2):198-219. https://doi.org/10.1590/s010350532003000200006

Paulsen, M. R., Mbuvi, S. W., Haken, A. E., Ye, B. ve Stewart, R. K. (2003). Extractable starch as a quality measurement of dried corn. Applied Engineering in Agriculture 19: 211-217. https://doi.org/10.13031/2013.13097

R Core Team, (2019) R: a language and environment for statistical computing. R Foundation for Statistical Computing, Vienna. http://www.R-project.org/

Redaelli R., Alfieri M.ve Cabassi G. (2016). Development of a NIRS calibration for total antioxidant capacity in maize germplasm. Talanta, 154:164-168. https://doi.org/10.1016/j.talanta.2016.03.048

Sabanc1, S. (2016). Ege bölgesinde yetiştirilen bazı mısır (Zea mays L.) çeşitlerinin verim, kalite ve antioksidan aktivitelerinin belirlenmesi. Yüksek Lisans Tezi, Adnan Menderes Üniversitesi Fen Bilimleri Enstitüsü, Aydin

Sans, S., Ferré, J., Boqué, R., Sabaté, J., Casals, J., Simó, J. (2020). Estimating sensory properties with nearinfrared spectroscopy: a tool for quality control and breeding of 'Calçots' (Allium cepa L.). Agronomy, 10:828. https://doi.org/10.3390/agronomy 10060828

Williams, P. ve Norris, K.H. (1987). Near-infrared technology in the agricultural and food Industries. 2nd Edn., American Association of Cereal Chemists, Inc., St. Paul, MN., ISBN-13: 9780913250495, p 330.

Yi, L., Dong, N., Yun, Y., Deng, B., Ren, D., Liu, S.ve Liang, Y.(2016). Chemometric methods in data processing of mass spectrometry-based metabolomics: A review. Analytica Chimica Acta, 914:17-34. https://doi.org/10.1016/j.aca.2016.02.001 